disease. Whatever the extent of the risk (and it is not clear what the committee considers to be a "low" risk), in my view there is a very strong case for compensating the parents of those children who are handicapped by such a reaction.

Although evidence has been presented on behalf of the Association of Parents of Vaccine Damaged Children to the Royal Commission on Civil Liability and Compensation for Personal Injury, it is unlikely that legislation will ensue for some time, and at best it is unlikely to be retroactive. The Joint Committee on Vaccination would do well to back its benign reassurance about pertussis vacine with strong support for the speedy introduction of a State compensation scheme.

Hospital for Sick Children,

London WC1 Lambert, H J, Public Health Reports, 1965,
90, 365.

\section{Volunteers and the aftermath of stroke}

SIR,-The setting up of volunteer schemes for home visitors for dysphasic patients, as described in your leading article (13 September, $p$ 606) by Miss Valerie Eaton Griffith ( $p$ 633 ), is surely to be applauded in principle, but why do Miss Griffith and your correspondents (27 September, p 763) urge that such schemes should develop outside the existing speech therapy services? We see three dangers in setting up a separate autonomous system.

(1) Despite the present declarations from Miss Griffith and the Chest and Heart Association that volunteer schemes and professional speech therapy services can co-exist in parallel, economy-minded area health authorities may be tempted to jump to the conclusion that volunteer schemes can provide a cheap substitute for professional services for dysphasic patients. The glowing account that 21 out of 31 patients improved in speech after a few months of visiting by untrained and unpaid volunteers calls into question, if read uncritically, the value of the existing speech therapy services. It is true that, on several counts, the report does not stand up to critical examination-the patients were selected, the assessment procedures were not standardised, there was no untreated control group, some of the patients were also receiving professional speech therapy, and the evaluations of progress were largely made by people who had undertaken the therapy and people who were firmly committed to the scheme's success. But such reservations tend to get lost from view when schemes seem to offer solutions to difficult problems at little cost.

(2) Dysphasia is a complex subject about which continuing research is constantly providing new insights, particularly at the present time when a new discipline of "neurolinguistics" is developing; and surely it is not unreasonable to believe that the management of language therapy for dysphasic patients requires an awareness of this major area of study-requires, in fact, the professional training of a speech pathologist and therapist. Yet Miss Griffith suggests that the secret of the success of the volunteers is their very ignorance of this study and insight. One thing of which the professional speech therapist is aware is that the type of general stimulation therapy which volunteer schemes are offering may well be quite unsuitable for people with some kinds of dysphasic problems and could even be harmful. Speech therapists know all too well that they do not possess all the answers; in the present state of knowledge about dysphasia patients should be carefully assessed by modern techniques in order that therapeutic regimens can be individually designed for each patient, and reassessed, so that these regimens can be revised as therapy proceeds.

(3) There is a continuing need for the systematic collection and collation of data so that patterns of impairment can be compared with patterns of treatment and recovery. There is also an urgent practical need for scientifically based research into the effectiveness of all ways of coping with the rehabilitation of dysphasic patients. No one, surely, would advocate that this research should be undertaken by the untrained rather than by qualified professionals, but isn't this what has been happening ?

These seem to us to be compelling reasons why volunteer schemes should be fostered within the aegis of the professional speech therapy service rather than outside. If al those good intentions and hours of devoted work from volunteers are to be well directed, and if such schemes are to realise their potential usefulness, doctors who wish to refer patients to voluntary organisation should do so through a speeoh therapist, who can decide on whether this approach is suitable for the individual patient, plan a therapeutic programme, and supervise its implementation. If there is any magic in being untrained and uninformed, as Miss Griffith suggests (and we suspect there isn't), it needs to be complemented by informed guidance.

These views are representative of those expressed by senior colleagues in speech therapy and provide some indication of the general concern which is felt in relation to the article.

MARgaret EDWARDS

Department of Speech.

Department of Speech,

\section{Sudden fetal deaths}

SIR,-With the increasing use of continuous fetal heart monitoring there have been a number of anecdotal reports of sudden fetal death without warning. It is extremely important that the histories and fetal hear traces of these cases should be studied in detail if we are to make labour safe for the fetus.

I would be most grateful if any of your readers who have experience of such a case would write to me and, if possible, send a short clinical summary and the fetal heart trace. Hopefully, if sufficient cases are collected it will prove possible to make recommendations that will help to avoid these distressing unexpected intrapartum stillbirths.

R W BEARD

Department of Obstetrics and Gynaecology

St Mary's Hoøpital Medical School,

London W2 1PG

\section{Epilepsy}

SIR,-I read with interest Dr F B Gibberd's article (1 November, p 270) and would like to make the following comments.

(1) It is surprising in November 1975 to find an article on the treatment of epilepsy which does not mention sodium valproate. (2) In young ohildren presenting with convulsions it is important to consider the possibility of non-accidental injury, especially when fundal haemorrhages are seen. (3) The minor motor epilepsies, dismissed in two lines, are more common than petit mal and their treatment is different; it may include clonazepam, nitrazepam, sodium valproate, steroids, and, in resistant and severe cases, a ketogenic diet. (4) With the availability of sodium valproate in addition to ethosuximide there must now be little place for troxidone in the treatment of petit mal. (5) The prophylaxis of febrile convulsions is an open subject; the evidence as regards regular anticonvulsant prophylaxis is contradictory and there is little evidence that intermittent phenobarbitone is useful.

D P ADDY

Department of Paediatrics,

Birmingham

SIR,-Although not mentioned in Dr F B Gibberd's article on the treatment of epilepsy (1 November, $p$ 270), a neonatal withdrawal syndrome has been associated with barbiturate use in pregnancy. ${ }^{1-3}$ The prevention of this syndrome might be another valid reason for stopping treatment before pregnancy in attack-free patients.

Because the age of onset of symptoms ranges from $30 \mathrm{~min}$ to 14 days $^{1}$ this condition should be borne in mind both during hospital stay and after discharge in any infant of an epileptic mother.

I BLUmenthal

Department of Child Health

University of Aberdeen

Desmond, M M, et al, fournal of Pediatrics, 1972, 80. 190 .

Bleyer. W A, and Marshall, $R$ E. Foumal of the
American Medical Association, 1972, 221, 185 .

American Medical Association, 1972, 221, 185.
Martinez, G, and Synder, R D, Neurology, 1973, 23, 381.

\section{Infective agent in infantile gastroenteritis}

SIR,-Dr B Rowe and Mr R J Gross (18 October, $p$ 162) are right to take up the cudgels in defence of some strains of Escherichia coli as causes of infantile enteritis and to remind us of the difficulties and limitations of routine bacteriological methods. Yet much of the evidence for the enteropathogenicity of $E$ coli strains for man rests on similar observations of association with disease as have been reported for some of the viruses. A combined bacteriological and virological approach is required to define and distinguish the aetiological roles of these bacteria and viruses, together or separately, with due attention to the possibility of spurious associations. Difficulties of proof, particularly in neonates, may necessitate ultimately accepting such circumstantial evidence as the basis of guilt, however.

If alteration of the intestinal contents by viral diarrhoea favours selection of certain $E$ coli types rather than others these types will show a secondary, not causal, association with the diarrhoea. If some of the viruses are coliphages they likewise may show spurious association with diarrhoea, unless by analogy with diphtheria the phages confer pathogenicity on the bacteria. If either bacterium or virus causes diarrhoea in a host carrying the other type of organism the diarrhoeal condition will favour simultaneous dissemination of both agents so that both may show association with diarrhoea in a particular outbreak. Similarly both agents, or whichever of them the investigator was equipped to detect, might show association with diarrhoea in an outbreak due to neither but to a third and undetected agent. 